\title{
Converging Technologies, Shifting Boundaries
}

\author{
Tsjalling Swierstra $\cdot$ Marianne Boenink • \\ B. Walhout • R. Van Est
}

Received: 5 November 2009 / Accepted: 5 November 2009/Published online: 3 December 2009

(C) The Author(s) 2009. This article is published with open access at Springerlink.com

At the beginning of the 21 century, most people are no longer surprised by technological revolutions. The twentieth century brought us information technology and biotechnology: key technologies for pioneering innovations such as the computer, the Internet and genetically modified plants. In the transition to the twenty-first century, two other important developments: nanotechnology (the research and design of materials at the smallest level possible) and cognitive science came along too.

But that will not be the end of it if we are to believe the National Science Foundation (NSF). At the end of 2002, Roco and Bainbridge, the organizers of the workshop 'Converging Technologies: Improving Human Performance' did not just announce the next revolution in science and technology, but a whole new era, a New Renaissance [4]. In their view, the boundaries between nanotechnology, biotechnology, information technology and the cognitive sciences (NBIC) will disappear and this will open up the way for an unprecedented holistic concept of what it means to be human, ranging from the way the tiniest components in our cells interrelate to the way we

T. Swierstra $(\bowtie) \cdot$ M. Boenink

University of Twente,

Enschede, Netherlands

e-mail: Tsjalling@Swierstra.net

B. Walhout $\cdot$ R. Van Est

Rathenau Institute,

The Hague, Netherlands think and feel. In the twenty-first century, according to their prophecy, human beings will be able to improve themselves radically.

In this trend to convergence, two characteristics keep recurring: informatization and miniaturization. Numerous processes, whether they take place in the organic world, the inorganic world, or in the world of cognition, are nowadays described in terms of obtaining, providing, processing and providing feedback on information. As a result, previously incompatible elements can now be connected to one another. Genes and other cell components contain a 'code' that can be 'cracked' and 'read' by biosensors; information from our minds can be 'loaded into a computer' and vice versa; persuasive technology controls our behaviour by confronting our brains with certain information; synthetic biology is conceivable because in the future we ourselves will combine and alter the information stored in genes so that we can steer organisms in a direction determined by us.

Secondly, converging technologies are founded on a far-reaching miniaturization of devices that has been made possible by the nanosciences and nanotechnology. These enable us to create contact points between brains and computers, between substances in our bloodstream and 'wet sensors', between someone's clothing and his or her intelligent living environment. It also means that we can put together cells from biological building blocks. Nanoproducts, such as minuscule electrodes and Radio Frequency IDentification (RFID) chips, are crucial for the explosive growth in information exchange and feedback too. 
At this early stage, it is difficult to argue for an optimistic or pessimistic stance towards these developments. There are, after all, many uncertainties involved. More specifically, we are facing a triple challenge here. Firstly, there is uncertainty regarding the facts: what is going to happen? A quick look at the past shows that many scientific and technological developments failed to keep their promise and meet the original expectations. As a scientific area develops, further investigation in that area tends to reveal that reality is much more complicated than was initially foreseen.

Secondly, there is uncertainty regarding norms: how desirable do we think that the possibilities created by the converging technologies are? This is a highly contested issue, especially because familiar normative frameworks tend to evolve in response to the emerging technologies $[2,7]$. When, for example, a new technology succeeds in creating new practical possibilities, the normative question arises: are these new actions morally allowed? Take for instance the discussion on prenatal genetic diagnostics: how far are we willing to broaden the criteria for the genetic selection of embryos? The question may also be raised in reverse: when technology provides people with new means to act, they may be morally obliged to do so. Not only do new interests and desires follow in the wake of new technologies (after all, supply influences demand), but these technologies often result in new bans, rights, duties and responsibilities as well. And in all likelihood, this will be also the case with converging technologies.

Thirdly, emerging technologies sometimes challenge the interpretative frameworks we use to categorize reality. Facts, norms and values are not things that we observe directly. Our perception is always mediated through culturally determined concepts and classification schemes. These schemes jointly make up what is known as our 'symbolic order', a concept coined by the famous anthropologist Mary Douglas [1]. The symbolic order categorizes reality by drawing boundaries. It applies fundamental distinctions, for instance between life and death, man and woman, human and thing, human and animal, organic and inorganic, body and mind, inside and outside, guilty and innocent, fate and human intent, rational and irrational, natural and artificial, receiving and making, healthy and sick, active and passive, normal and abnormal, and so on. It is this order that determines how we understand ourselves, our world and our place in that world.
In our daily lives we confidently set course based on the compass of such obvious boundaries and distinctions. But new technologies sometimes bring us face to face with unexpected obstacles, possibilities, questions and uncertainties that shake the foundations of this symbolic order [5]. Because the symbolic order influences not only our account of the facts, but also our norms and values, this third form of uncertainty is the most fundamental.

This special issue of NanoEthics examines this third form of uncertainty in particular. How is the existing symbolic order challenged by converging technologies? How does this challenge affect attempts to subject these new technologies to a normative judgement? And how can we perhaps find a way out of the problems sketched? These questions are central to the following papers.

It is worthwhile to contrast our approach with the body of work in ethics that aims to clarify the meaning of existing (moral) concepts. By way of thought experiments, for example, philosophers examine the implications and boundaries of life and death, human and animal, body and mind as well as other concepts. And indeed, some of the current technological developments were part of such thought experiments. Our approach in this special issue differs from this more traditional ethical approach. Our starting point is the pragmatist conviction that the symbolic order created by humans is firmly rooted in practices and ways of living [3]. As a consequence, the symbolic order is not static but evolves with these practices. Technological innovation is an important cause of change and as such of 'symbolic confusion'.

We do not want to imply, however, that concepts just passively follow practice. When practical developments and symbolic order do not fit anymore, adjustments in either direction may be necessary [8]. Whether or not specific concepts will be replaced by alternative concepts and distinctions is an open question. Even if concepts keep being used, however, they are likely to be reinterpreted or specified in view of the new practices. It is this potential evolution of meaning the authors in this special issue are exploring.

The first four contributions in this special issue of Nano-ethics analyze different fields of technological convergence: brain-machine interaction, persuasive technologies, molecular medicine and synthetic biology, respectively. In each case, at least two of the four NBIC key technologies (nanotech- 
nology, biotechnology, information technology and cognitive science) converge.

Maartje Schermer discusses brain-machine interactions whereby brains and computers are connected to one other. All four technologies play a role here. Many boundaries blur in this application, including those between man and machine, appearance and reality, experience and design of the world, and inside and outside our bodies (in the case of the exoskeleton connected to the brain).

Peter Paul Verbeek investigates the so-called persuasive technologies (technologies that are designed to influence our behaviour and 'nudge' it in a specific direction) [6]. These technologies are based on the interaction between information technology and cognitive science and they problematize the symbolic boundary between humans agents and artefacts. Moreover, they shift the meaning of crucial moral concepts like freedom and responsibility. Verbeek argues that these new technologies urge us to blur the boundaries between humans and technologies at the level of conceptual and moral frameworks.

Marianne Boenink writes about the convergence of biotechnology, information technology and nanotechnology in molecular medicine and investigates how this convergence affects current thinking about health and disease. New medical technology constructs its own image of the 'natural' history of disease and in the process shifts the boundary between 'normal' and 'deviant' bodily functioning. Molecular medicine on the one hand seems to build on a cascade model of disease, thereby reinforcing tendencies towards early diagnosis and treatment. On the other hand, it aims at showing personal patterns in bodily functioning, which opens up possibilities for highly individual definitions of what is and is not experienced as disease. Boenink discusses both the tensions and the opportunities implied by these shifts in our conceptualization of 'disease' and 'health'.

Synthetic biology, which is endeavouring to create artificial life forms, takes centre stage in Henk van den Belt's contribution. Here, too, information technology and nanotechnology make their influence on biotechnology felt. Synthetic biology challenges such fundamental distinctions as those between dead and living, natural and artificial, the evolved and the designed. Van den Belt analyses two arguments often used to articulate uneasiness about these developments: the 'playing God' and 'following Frankenstein' arguments. He argues that the concerns voiced in these arguments are often narrowly anthropocentric. As long as synthetic biology does not directly affect human life, we will probably be able to deal with the conceptual shifts.

The final contribution by Swierstra, Van Est, and Boenink, reflects on the technological developments and conceptual shifts laid bare in the four preceding papers. Do converging technologies in general confront our symbolic order with specific challenges and if so, what does this mean for policy and politics? The authors argue that NBIC-convergence extends a particular form of 'making' - building - that was formerly restricted to inorganic matter, to organic life, including human life. This shift is potentially far-reaching in its consequences, as up to now living organisms were respected as somehow special because they have their own 'action program', as being 'agents' who deserve a form of respect that we do not owe to inorganic matter. For humans, the question becomes prominent how much control over the outer and inner world is compatible with the good life. The authors conclude that public debate on converging technologies should evolve around the central issue of striking the right balance between control and acceptance.

This special issue finds its origin in a book commissioned by the Dutch Rathenau Institute, an independent institute for technology assessment that advises politicians, policy makers and the general public on issues on the interface between science, technology and society. The book was edited by Tsjalling Swierstra, Marianne Boenink, Rinie van Est and Bart Walhout, published in 2009 and titled Leven als bouwpakket (Life as a construction kit) [9]. The contributions to this issue are revised and updated versions of the chapters of that book. The authors thank the Rathenau Institute for providing funds for translating and checking the contributions in this issue of Nanoethics. They also want to thank the anonymous reviewers who have greatly contributed to improve the concept articles.

Open Access This article is distributed under the terms of the Creative Commons Attribution Noncommercial License which permits any noncommercial use, distribution, and reproduction in any medium, provided the original author(s) and source are credited. 


\section{References}

1. Douglas M (1966) Purity and danger: an analysis of the concepts of pollution and taboo. Routledge, London

2. Grunwald A (2007) Converging technologies: visions, increased contingencies of the conditio humana, and search for orientation. Futures 39(4):380-392

3. Keulartz J, Schermer M, Korthals M, Swierstra T (2004) Ethics in technological culture: a programmatic proposal for a pragmatist approach. Sci Technol Human Values 29 (1):3

4. Roco MC, Bainbridge WS (2002) Converging technologies for improving human performance: integrating from the nanoscale. J Nanopart Res 4(4):281-295. doi:10.1023/ A:1021152023349
5. Smits M (2006) Taming monsters: the cultural domestication of new technology. Technol Soc 28(4):489-504. doi:10.1016/j. techsoc.2006.09.008

6. Sunstein CR, Thaler R (2008) Nudge: improving decisions about health, wealth and happiness. Yale University Press, New Haven

7. Swierstra TE (2003) De wisselwerking tussen ethiek en technologie. Naar een moderne technologie-ethiek. In: Devisch I, Verschraegen G (eds) De verleiding van de ethiek. Over de plaats van ethische argumenten in de huidige cultuur. Boom, Amsterdam, pp 154-171

8. Swierstra T, Rip A (2007) Nano-ethics as NEST-ethics: patterns of moral argumentation about new and emerging science and technology. NanoEthics 1(1):3-20

9. Swierstra T, Boenink M, Walhout B, Van Est R (2009) Leven als bouwpakket. Ethisch verkennen van een nieuwe technologische golf. Rathenau Institute, The Hague 